\title{
Методичний підхід щодо оцінювання ефективності системи метрологічного обслуговування засобів вимірювального контролю параметрів зразків озброєння та військової техніки
}

\author{
Андрій Дядечко ${ }^{1 \text { A }}$ \\ А Національний університет оборони України імені Івана Черняховського, пр-кт Повітрофлотський, 28, г. Київ, 03049, Україна
}

Received: June 6, 2021 | Revised: June 19, 2021 | Accepted: June 30, 2021

DOI: $10.33445 /$ sds.2021.11.3.17

\begin{abstract}
Анотація
Впровадження стандартів НАТО в сфері оборони вимагає здійснення певних кроків щодо модернізації існуючих та виготовлення нових зразків озброєння та військової техніки, а також засобів ії технічного обслуговування до яких відносяться вимірювальні прилади, системи та комплекси за допомогою яких здійснюється контроль параметрів озброєння.

Поряд з тим, на сьогоднішній день процес метрологічного обслуговування засобів вимірювального контролю параметрів зразків озброєння та військової техніки потребує удосконалення, що забезпечить надійне функціонування засобів вимірювального контролю та зразків озброєння в цілому.

Для досягнення оптимальної роботи системи метрологічного обслуговування засобів вимірювального контролю параметрів зразків озброєння та військової техніки необхідно проводити оцінку ефективності їі роботи за визначеними показниками.

В статті запропоновано методичний підхід щодо оцінки ефективності системи метрологічного обслуговування засобів вимірювального контролю параметрів зразків озброєння та військової техніки, зокрема за показниками надійності, часом реагування системи на відмови та показниками достовірності результатів вимірювального контролю.
\end{abstract}

Ключові слова: метрологічне обслуговування, озброєння та військова техніка, засоби вимірювального контролю, оцінка ефективності.

\section{Постановка проблеми}

Метрологічне обслуговування (МлОб) засобів вимірювального контролю (ЗВК) параметрів зразків озброєння та військової техніки (ОВТ) проводиться з метою надання обгрунтованих висновків щодо справності, і як наслідок, придатності ЗВК до застосування за призначенням. Проте на сьогоднішній день система метрологічного обслуговування (СМлОб) ЗВК параметрів зразків ОВТ потребує удосконалення 3 урахуванням сучасних вимог до зразків ОВТ та тенденцій розвитку Збройних Сил (ЗС) України. Щоб запобігти надмірних витрат ресурсів під час проведення МлОб ЗВК параметрів зразків OBT, забезпечити правильне прийняття рішення щодо технічного стану ЗВК та зразка ОВТ в цілому, необхідно отримати оцінки, що дозволять проводити аналіз стану ЗВК параметрів ОВТ та синтезувати оптимальну СМлОб ЗВК параметрів ОВТ за визначеними показниками ефективності, зокрема за показниками надійності, часом реагування системи на відмови в роботі ЗВК, показниками точності та достовірності.

\footnotetext{
1 *Corresponding author: ад’юнкт кафедри технічного забезпечення, e-mail: andrewvvs@gmail.com, ORCID: 0000-0003-0191-8326
} 


\section{Аналіз останніх досліджень та публікацій}

В останніх дослідженнях вирішувались різноманітні задачі оцінки ефективності складних систем, які придатні й для СМлОб ЗВК параметрів зразків ОВТ [1-5, $14-17]$. Як недолік в зазначених роботах слід відмітити, що під час оцінки ефективності вони не враховують показники надійності ЗВК та ОВТ, показники достовірності результатів метрологічного обслуговування ЗВК, а враховують тільки показники точності та часові показники в загальному вигляді. Разом з тим в зазначених публікаціях не оцінюється час реагування системи на відмови в роботі
ЗВК, що не дозволяє оцінити готовність системи реагувати на аварійні ситуації. В [6] досліджується комплексний економічний показник ефективності проведення МлОб, по якому можливо розрахувати оптимальну періодичність проведення МлОб ЗВК параметрів зразків ОВТ, проте не враховано оцінку економічного ефекту від безперервного контролю стану ЗВК параметрів зразків ОВТ. Тому необхідно більш досконалі показники оцінки ефективності проведення МлОб зВК параметрів ОВТ.

\section{Постановка завдання}

Для забезпечення якісного проведення робіт з МлОб ЗВК параметрів ОВТ необхідно мати оптимально побудовану СМлОб, яка спроможна ефективно виконувати свої функції. Основною функцією СМлОб ЗВК параметрів зразків ОВТ $€$ підтримання ЗВК параметрів зразків ОВТ у готовності до застосування.
Отже, метою статті $\epsilon$ удосконалення методичних підходів оцінювання ефективності СМлОб ЗВК параметрів ОВТ за рахунок оцінки показників надійності, часу реагування системи на відмови та показників достовірності результатів МлОб ЗВК параметрів ОВТ.

\section{Виклад основного матеріалу}

Ефективність проведення МлОб характеризується рядом показників, які визначають ступінь досягнення необхідного результату МлОб. Методичний підхід щодо оцінки ефективності СМлОб ЗВК параметрів зразків ОВТ, що пропонується, дозволяє визначити ефективність ї̈ роботи за показниками надійності ЗВК та ОВТ в цілому, часом реагування системи на відмови в роботі ЗВК, показниками точності та достовірності.

Характерною особливістю сучасного розвитку ОВТ $\epsilon$ широке впровадження елементів та пристроїв автоматики та інформаційно-вимірювальної техніки у процес виконання ним завдань за призначенням. В умовах сучасної економіки, автоматизація $€$ одним з основних напрямків розвитку науково-технічного прогресу. I, звичайно, покращення ефективності та якості застосування зразків ОВТ не можливе без оцінювання надійності їх функціонування.
Разом з тим підвищення складності зразків ОВT, засобів їх технічного обслуговування, умов їх експлуатації і відповідальності завдань, які на них покладаються, також вимагає оцінювання показників надійності їх функціонування [7].

Необхідність оцінки показників надійності ЗВК та ОВТ, параметри якої контролюються, під час оцінювання ефективності СМлОб зВК параметрів ОВТ обумовлена тим, що недостатня надійність ЗВК призводить до збільшення частки експлуатаційних витрат в порівнянні 3 загальними витратами на їх проектування, виробництво та використання. При цьому вартість проведення МлОб зВК параметрів зразків ОВТ може перевищувати вартість їх експлуатації. Крім того, відмови в роботі ЗВК параметрів зразків ОВТ призводять до різного роду наслідків: втратам важливої інформації, передчасному виходу з ладу вузлів та агрегатів зразків ОВТ i, як наслідок, зниження їх боєготовності. 
На початковому етапі експлуатації як ЗВК так i зразка ОВТ показники надійності визначаються на рівні, закладеному виробником. Визначають чотири групи показників надійності: показники безвідмовності, показники довговічності, показники збережуваності та показники ремонтопридатності. Кожна з груп містить в собі декілька одиничних показників які й характеризують надійність ЗВК та ОВТ як комплексну властивість зберігати у часі в установлених межах значення всіх параметрів, які характеризують здатність виконувати визначені функції в заданих умовах та режимах застосування, технічного обслуговування та транспортування [8].

В процесі експлуатації, при наявності статистичних даних про відмови в роботі ЗВК та ОВТ, показники надійності визначаються за відомими математичними залежностями. При оцінюванні ефективності СМлОб доцільно оцінювати показники надійності 3 групи показників безвідмовності, тому що ефективна робота СМлОб забезпечить утримання зазначених показників на необхідному для нормального функціонування ЗВК або ОВТ рівні. У разі зниження встановленого виробником рівня показників надійності можна зробити висновок, що СМлОб побудована не оптимально та потребує удосконалення.

При оцінюванні показників надійності зразків ОВТ, статистичні дані про відмови яких відомі, зазвичай використовують розподіл Вейбула-Гнеденка [9]. Відповідно до цього розподілу імовірність безвідмовної роботи в інтервалі $0-t$ :

$$
P(t)=\exp \left[-\left(\frac{t}{c}\right)^{b}\right]
$$

де $b \geq 0$ - параметр форми закону розподілу, який залежить від кількості відмов виробу (для ОВТ цей параметр перебуває в діапазоні від 2 до 5 [10];

$c \geq 0$ - параметр масштабу.

Щільність імовірності відмов дорівнює:

$$
f(t)=\frac{b}{c} \cdot\left(\frac{t}{c}\right)^{b-1} \cdot \exp \left[-\left(\frac{t}{c}\right)^{b}\right]
$$

Поділивши (2) на (1) отримуємо інтенсивність відмов:

$$
\lambda(t)=\frac{b}{c} \cdot\left(\frac{t}{c}\right)^{b-1}
$$

Очевидно, що при $b<1$ інтенсивність відмов монотонно зменшується, а при $b>1$ (що відповідає зразкам ОВТ) монотонно збільшується.

При оцінюванні показників надійності ЗВК параметрів зразків ОВТ широко використовується розподіл Релея, який достатньо повно описує поведінку радіоелектронних засобів і їх елементів при наявності статистичних даних про відмови [9]. Відповідно до цього розподілу імовірність безвідмовної роботи ЗВК в інтервалі $0-t$ визначається зі співвідношення:

$$
P(t)=\exp \left[-\frac{t^{2}}{2 s^{2}}\right]
$$

де $s$ - параметр закону розподілу.

щільність імовірності відмов визначається за формулою:

$$
f(t)=\left(\frac{t}{s^{2}}\right) \cdot \exp \left[-\frac{t^{2}}{2 s^{2}}\right]
$$

Інтенсивність відмов ЗВК дорівнює:

$$
\lambda(t)=\frac{t}{s^{2}}
$$

Співвідношення (1) - (6) підтверджують зростання інтенсивності відмов зразків ОВТ та ЗВК їх параметрів у міру виробітку їх ресурсу. Отже, чим більше техніка пропрацювала, тим частіше необхідно проводити ії МлОб з метою визначення її придатності до подальшого застосування, оскільки саме проведення метрологічного обслуговування сприяє визначенню їх технічного стану (справності чи несправності). Якщо зразок ОВТ за результатами МлОб визнається непрацездатним, то за допомогою ремонту чи регулювання він доводиться до справного стану. Тому можна стверджувати, що проведення МлОб ЗВК параметрів зразків ОВТ підвищує вірогідність того, що зразок OBT, параметри якого контролюються визначеними ЗВК, буде справним протягом подальшого міжперевірочного інтервалу. Саме підтримання показників надійності ЗВК 
та ОВТ на визначеному рівні при проведенні їх МлОб характеризує високу ефективність роботи СМлОб.

Поряд з тим, для підтримання показників надійності на визначеному рівні, необхідно щоб СМлОб забезпечувала вчасне та оперативне реагування на виникнення відмов в роботі ЗВК параметрів зразків ОВТ. Тому, як одним з показників ефективності роботи СМлОб ЗВК параметрів зразків ОВТ пропонується визначити імовірність своєчасного виявлення відмов $\mathrm{P}_{\mathrm{B}}(\mathrm{t})$, оцінювання якого дозволить визначити спроможність СМлОб вчасно та адекватно реагувати на відмови ЗВК, щоб запобігти виходу з ладу вузлів та агрегатів, а також зразків ОВТ в цілому. Якщо СМлОб не спроможна вчасно реагувати на відмови ЗВК, як показано на рис. 1, це призведе до негативного впливу на стан параметрів вузлів та агрегатів, вихід їх з ладу та відмову зразка OBT.

Отже, імовірність своєчасного виявлення відмови визначається за формулою:

$$
P_{\mathrm{B}}(t)=e^{-\frac{t}{T_{\mathrm{A}}}}
$$

де, $t$ - час на виявлення та усунення відмови;

$T_{\text {д }}$ максимально допустимий час на виявлення та усунення відмови.

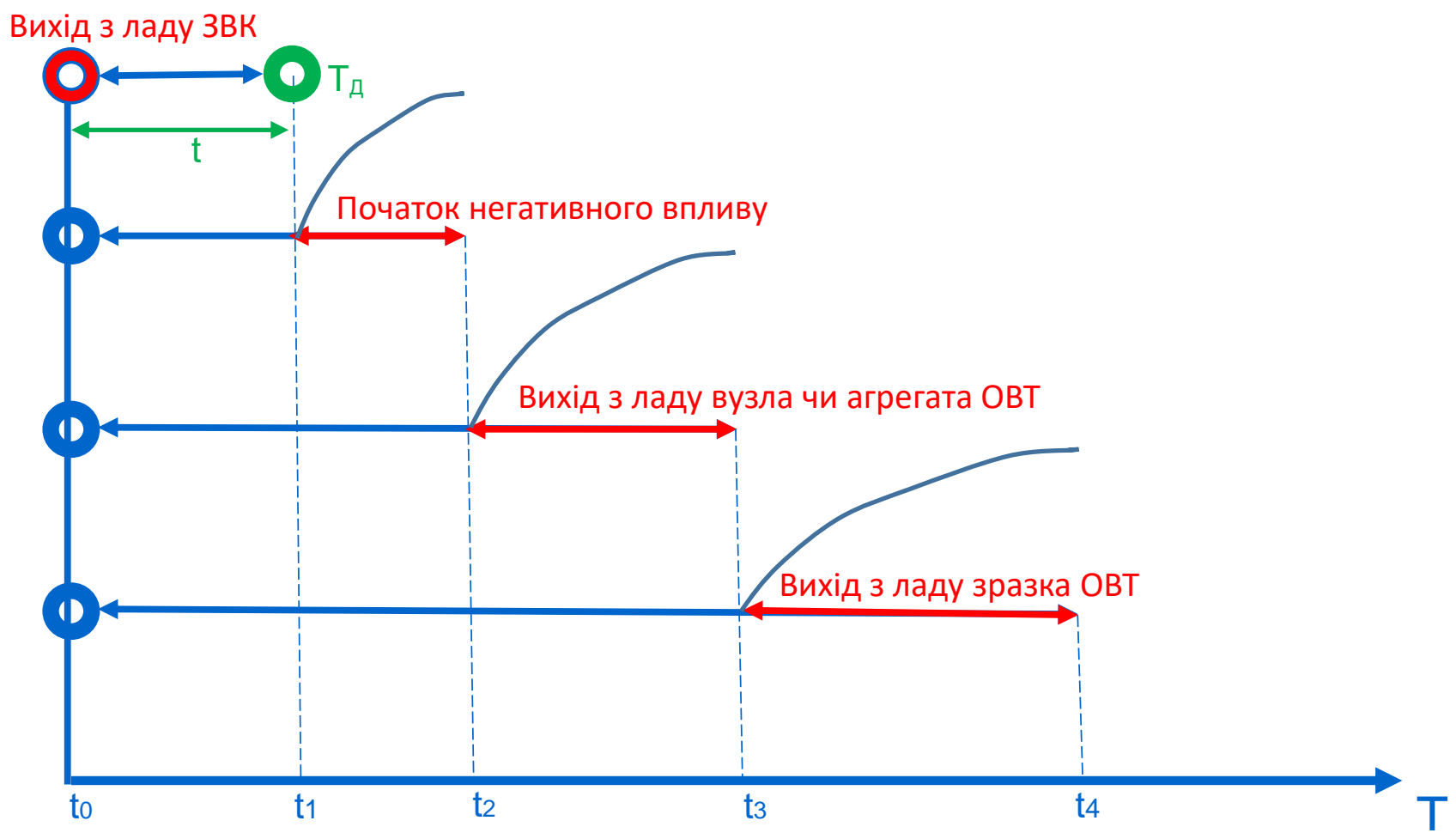

Рисунок 1 - Залежність справного стану зразка ОВТ від своєчасного виявлення відмови в роботі ЗВК

Якщо в момент часу $t_{0}$ (рис.1) ЗВК параметрів зразків ОВТ вийшов $з$ ладу i протягом інтервалу часу $t=\left(t_{0} ; t_{1}\right)$ (де $\left.t_{1}=T_{\text {д }}\right)$ не виявити вихід його з ладу та не усунути відмову, то з моменту часу $t_{1}$ починається негативний вплив на стан параметрів основних вузлів та агрегатів зразка ОВТ параметри яких вимірюються (контролюються) зазначеним ЗВК. Відповідно з моменту часу $t_{2}$ починається вихід з ладу вузлів та агрегатів, а з моменту часу $t_{3}-$ вихід з ладу зразка ОВТ. Оскільки до моменту виявлення відмови в роботі ЗВК його показання про стан параметрів вузлів та агрегатів приймається як їх дійсне значення, то чим більше часу пройде з моменту виходу ЗВК з ладу, тим імовірність виходу з ладу вузла чи агрегату збільшується, як і імовірність виходу з ладу зразка ОВТ в цілому. Тому оцінювання імовірності своєчасного 
виявлення відмов ЗВК параметрів ОВТ системою МлОб має важливе значення при синтезі оптимальної системи МлОб.

Оскільки СМлОб ЗВК параметрів зразків ОВТ $€$ складовою частиною системи метрологічного забезпечення (СМл3), а основною функцією СМлЗ є своєчасне та повне виконання комплексу заходів спрямованих на забезпечення єдності вимірювань та достовірності вимірювального контролю параметрів зразків ОВТ [11], то оцінку ефективності СМлОб доцільно проводити також і за показниками точності та достовірності.

Як правило, показником точності СМлОб визначається сумарна похибка вимірювань значень характеристик ЗВК.

Так, при прямих вимірюваннях, незалежних похибках ЗВК, нормальних законах розподілу похибок, що підсумовуються, сумарна похибка визначається за формулою:

$$
D_{\Sigma}=\sqrt{\Delta^{2}+\sum_{j=1}^{r} D_{j}^{2}}
$$

де $\Delta$ - межа допустимої абсолютної основної похибки засобу вимірювання;

$D_{\mathrm{j}}$ - межі допустимих абсолютних похибок: додаткових (від функції впливу) в заданих робочих умовах вимірювань; похибок, викликаних пристроями та лініями зв'язку;

$$
r \text {-кількість } j \text {-тих похибок. }
$$

При прямих вимірюваннях, коли закон розподілу хоча $б$ однієї з похибок, що підсумовуються, відмінний від нормального, сумарна похибка визначається за формулою:

$$
D_{\Sigma}=K_{\Pi} \sqrt{\left(\frac{\Delta}{K_{0}}\right)^{2}+\sum_{j=1}^{r}\left(\frac{D_{j}}{K_{j}}\right)^{2}}
$$

де $K_{0}$ i $K_{\mathrm{j}}$ - коефіцієнти переходу від похибок $\Delta$ та $D_{\mathrm{j}}$ до відповідних середньоквадратичних похибок;

$K_{\text {п }}$ - коефіцієнт переходу від сумарної середньоквадратичної похибки до сумарної граничної похибки $D_{\Sigma}$.

Коефіцієнти $K_{0}, K_{j}$ та $K_{n}$ при різних законах розподілу похибок $\Delta, D_{j}$ та $D_{\Sigma}$ у відповідних генеральних сукупностях мають значення [12] приведені у табл. 1.

Таблиця 1 - Генеральні сукупностей

\begin{tabular}{|l|c|}
\hline Закон розподілу похибок $\Delta, D_{j}$ та $D_{\Sigma}$ & Значення коефіцієнтів $K_{0}, K_{j}$ та $K_{n}$ \\
\hline Нормальний & 3,0 \\
Рівної імовірності & 1,73 \\
Симпсона (трикутний) & 2,45 \\
Трапецієвидний & 2,3 \\
Антимодальний I & 1,4 \\
Антимодальний II & 1,3 \\
Релея & 5,25 \\
\hline
\end{tabular}

При прямих вимірюваннях, але при наявності кореляційних зв'язків між усіма або деякими похибками, що підсумовуються, сумарна похибка визначається за формулою:

$D_{\Sigma}=C \sqrt{\left(\frac{\Delta}{K_{0}}\right)^{2}+\sum_{j=1}^{r}\left(\frac{D_{j}}{K_{j}}\right)^{2}+2 \sum_{j<\xi} K_{j \xi}}$

де $K_{j \xi}$ - кореляційні моменти, які характеризують зв'язки між похибками, що підсумовуються.
Якщо межі допустимих абсолютних основних похибок для систематичних та випадкових складових нормуються окремо, то у формулі (8) член $\Delta^{2}$ слід замінити виразом

$$
\left[\Delta_{\text {с.म }}^{2}+\left(3 \sigma_{\text {д }}(\stackrel{\circ}{\Delta})\right)^{2}\right]
$$

а у формулах (9), (10) член $\left(\frac{\Delta}{K_{0}}\right)^{2}-$ виразом

$$
\left[\left(\frac{\Delta_{\text {с. }}}{\kappa_{0}}\right)^{2}+\left(\sigma_{\text {д }}(\stackrel{\circ}{\Delta})\right)^{2}\right],
$$


де $\Delta_{\text {с.д }}$ - межа допустимої систематичної складової похибки засобів вимірювання даного типу;

$$
\sigma_{\text {д }}(\Delta) \text { - межа допустимого середнього }
$$
квадратичного відхилення випадкової складової похибки засобів вимірювань даного типу.

Значення $\Delta, D_{j}, \Delta_{\text {с.д }}$ та $\sigma_{\text {д }}(\Delta)$ беруться із експлуатаційної чи технічної документації на засоби вимірювання, пристрої та лінії зв'язку.

При опосередкованих вимірюваннях, коли параметр $Y=f\left(x_{1}, \quad x_{2}, \ldots, x_{n}\right) \quad$ функціонально пов'язаний $3 n$ параметрами $x_{1}, x_{2}, \ldots, x_{n}$, що вимірюються прямим способом, сумарна похибка вимірювань визначається за формулою:

$$
D_{\Sigma}=\sqrt{\left[\frac{\partial f\left(x_{1}, x_{2}, \ldots, x_{n}\right)}{\partial x_{1}} D_{\Sigma_{x_{1}}}\right]^{2}+\left[\frac{\partial f\left(x_{1}, x_{2}, \ldots, x_{n}\right)}{\partial x_{2}} D_{\Sigma_{x_{2}}}\right]^{2}+\ldots+\left[\frac{\partial f\left(x_{1}, x_{2}, \ldots, x_{n}\right)}{\partial x_{n}} D_{\Sigma_{x_{n}}}\right]^{2}}
$$

де $D_{\Sigma_{x_{n}}}$ - сумарна похибка вимірювань $x_{n}$ го параметра, що визначається за формулою (8), (9) або (10).

Поряд $з$ показниками точності, під час проведення вимірювання (контролю) параметрів ЗВК, необхідно визначити та оцінити показники достовірності, щоб запобіпи виникненню помилкових або невиявлених відмов ЗВК параметрів зразків OBT.

При оцінюванні ефективності СМлОб нами запропоновано виразити показники достовірності як залежності апостеріорної ймовірності помилкової $\alpha$ і невиявленої $b$ відмов від помилок контролю першого $\alpha_{i}$ та другого $b_{i}$ роду за $i$-м ЗВК, які визначаються зі співвідношень (12), (13) [13]:

$$
\begin{gathered}
\alpha=1-\prod_{i=1}^{N}\left(1-\alpha_{i}\right) \\
\beta=\frac{\prod_{i=1}^{N}\left[P_{c i}\left(1-\alpha_{i}-\beta_{i}\right)+\beta_{i}\right]-\prod_{i=1}^{N}\left(1-\overline{P_{c i}}\right)\left(1-\alpha_{i}\right)}{1-\prod_{i=1}^{N}\left(1-\overline{P_{c i}}\right)}
\end{gathered}
$$

де $\alpha_{i}=P_{\Pi в} / P_{c}$;

$B_{i}=P_{H B} /\left(1-P_{c}\right)$;

$P_{\Pi B}$ і $P_{H в}$ - апріорна ймовірність помилкової і невиявленої відмов $i$-го ЗВК;

$\overline{P_{c i}}-$ ймовірність того, що параметри $i$-го ЗВК знаходяться поза межами допуску;

$P_{c}=\prod_{i=1}^{N} P_{c i}-$ ймовірність того, що виміряні значення параметрів всіх $3 B К$, що контролюються, знаходяться в межах допуску;
$\overline{P_{c}}=\prod_{i=1}^{N} \overline{P_{c i}}=1-P_{c}-$ ймовірність того, що виміряні значення параметрів хоча $\sigma$ одного ЗВК, що контролюються, знаходяться поза межами допуску.

Аналіз співвідношення (13) показує, що другий доданок чисельника $€$ рівним нулю, якщо параметри хоча 6 одного ЗВК, що контролюються, знаходяться поза межами допуску, тобто $\overline{P_{c i}}=1$. В цьому випадку знаменник дорівнює одиниці. Якщо виміряні значення параметрів всіх ЗВК, що контролюються, знаходяться в межах допуску, то при вимірюваннях можлива тільки помилка контролю першого роду, і її визначають за формулою (12). Якщо виміряні значення параметрів хоча б одного ЗВК, що контролюються, знаходиться поза межами допуску, то при вимірюваннях можлива тільки помилка другого роду, і її визначають за співвідношенням (13).

3a допустимими значеннями апостеріорної ймовірності помилок контролю першого $\alpha^{\text {म }}=\frac{\mathrm{P}_{\Pi \mathrm{B}}^{\mathcal{B}}}{\mathrm{P}_{c}}$ і другого $\beta^{\text {म }}=\frac{\mathrm{P}_{\mathrm{HB}}^{\mathrm{A}}}{\overline{\mathrm{P}_{c}}}$ роду визначимо вимоги до показників достовірності контролю кожного ЗВК параметрів конкретного зразка ОВТ:

$$
\begin{gathered}
1-\prod_{i=1}^{N}\left(1-\alpha_{i}\right) \leq \alpha^{\text {म }}, \\
\frac{\prod_{i=1}^{N}\left[P_{c i}\left(1-\alpha_{i}-\beta_{i}\right)+\beta_{i}\right]-\prod_{i=1}^{N}\left(1-\overline{P_{c i}}\right)\left(1-\alpha_{i}\right)}{1-\prod_{i=1}^{N}\left(1-\overline{P_{c i}}\right)} \leq \beta^{\text {म }},
\end{gathered}
$$

При використанні апостеріорної оцінки достовірності результату контролю граничні значення помилок контролю за кожним параметром ЗВК $€$ рівними допустимій 
ймовірності помилкової і невиявленої відмов ЗВК в цілому.

Заключними етапом оцінювання ефективності СМлОб доцільно визначити оцінку економічної ефективності і присвятити подальше дослідження щодо ефективності сМлоб саме питанням економічної ефективності поряд з зазначеними вище показниками.

\section{Висновки}

Таким чином оцінювання ефективності СМлОб за визначеними показниками дозволить синтезувати оптимальну СМлОб, що забезпечить якісне проведення МлОб зВК параметрів зразків ОВТ та ефективне прийняття рішень щодо придатності ЗВК до застосування за призначенням i, як наслідок, вірне оцінення стану зразка ОВТ в цілому за визначеними характеристиками ЗВК його параметрів.

Як результат можна сформулювати удосконалену методику оцінювання ефективності СМлОб за визначеними показниками, яка складатиметься 3 наступних етапів:

1. Оцінка показників надійності та оцінка ймовірності своєчасного виявлення відмови
ЗВК параметрів зразків ОВТ.

2. Оцінка показників точності вимірювання характеристик ЗВК та достовірності результатів вимірювання.

3. Оцінка показників економічної ефективності.

Отримані результати дозволяють проаналізувати існуючу СМлОб ЗВК параметрів зразків ОВТ, визначити ї̈ недоліки й шляхи їх усунення.

Подальші дослідження можуть бути направлені на визначення показників економічної ефективності СМлОб та побудову оптимальної СМлОб зВК параметрів зразків ОВТ 3 урахуванням отриманих показників ефективності.

Київ, НУОУ ім. І. Черняховського, 2018, № 2 (32), С. 125-134.

5. Чекрыжев Н.В., Коптев А.Н. К оценке эффективности процесса технического обслуживания бортовых систем воздушных судов. Научный вестник МГТУ ГА, Москва, 2015, № 219, С. 57-64.

6. Чинков В.Н., Герасимов С.В., Яковлев М.Ю. Комплексный экономический показатель эффективности метрологического обслуживания сложных технических объектов. Системи обробки інформації, Харків, ХВУ, 2001, Вип. 5(15), с. 7-12.

7. Васілевський О. М., Поджаренко В. О. Нормування показників надійності технічних засобів. Навчальний посібник, Вінниця, ВНТУ, 2010, 129 с.

8. ДСТУ 2860-94. “Надійність техніки. Терміни та визначення". Держспоживстандарт України, Київ, 1994. 33 с.

9. Герасимов С. В., Козлов В. Є., Шамаєв Ю. П. Метрологічна надійність засобів 
вимірювальної техніки: Навчальний посібник. - Харків: ХУПС, 2006. - 175 с.

10. Бабков Ю.П. Основы теории надежности, технического обслуживания и ремонта вооружения и военной техники войск ПВО Сухопутных войск. - Харьков.: ХВУ, 1996. $237 \mathrm{c}$.

11. Про затвердження Положення про метрологічну службу Міністерства оборони України та Збройних Сил України. - К.: 2017. - 15 с. - (Наказ Міністерства оборони України від 24.05.2017 № 288 (зі змінами)).

12. ДСТУ ГОСТ 8.009:2008 “ГСИ. Нормируемые метрологические характеристики средств измерений". Держспоживстандарт України, Київ, 2008.

13. Дядечко А. О., Кузнецов І. Б., Марценківський В. Т. Алгоритм контролю параметрів озброєння та військової техніки для інформаційно-вимірювальної системи військового призначення // Сучасні інформаційні технології у сфері безпеки та оборони. № 3(36). Київ, НУОУ ім. І.Черняховського, 2019 р. с. 103-108.
14. Wang, Y., Wang, X., Wei, N. The Dicision Analysis for Cost-effectiveness of the Military Metrological support. Metrology \& Measurement Technology, 2007, The Second Artillery Measuring Station, Beijing 100085, China.

15. Girija Moona, Mukesh Jewariya \& Rina Sharma. Relevance of Dimensional Metrology in Manufacturing Industries. MAPAN Journal of Metrology Society of India, CSIR-National Physical Laboratory, New Delhi, India, 2019, № 34, p. 97-104.

16. Salvador Echeverría-Villagómez, Luis Zambrano, Guadalupe Rivera, Marlén López, Diana Guzmán, Francisco Rodriguez. Metrology Investment Projects for Process Effectiveness, NCSLI Workshop \& Symposium, July 2015, Grapeville, TX, USA.

17. Yuanqinga Li, Shilin Wu, Qi Zhang. Construct of Metrology Information Public Service System. 3rd International Conference on Material, Mechanical and Manufacturing Engineering (IC3ME 2015), 2015, p. 1296 1301, DOI: 10.2991/ic3me-15.2015.249.

\title{
Методический подход к оценке эффективности системы метрологического обслуживания средств измерительного контроля параметров образцов вооружения и военной техники
}

\footnotetext{
Андрей Дядечко * 1 А

* Corresponding author: ${ }^{1}$ адъюнкт кафедры технического обеспечения, e-mail: andrewvvs@gmail.com, ORCID: 0000-0003-0191-8326

А Национальный университет обороны Украины имени Ивана Черняховского, пр-кт Воздухофлотский, 28, г. Киев, 03049, Украина
}

\begin{abstract}
Аннотация
Внедрение стандартов НАТО в сфере обороны требует от нас осуществления определенных шагов по модернизации существующих и изготовление новых образцов вооружения и военной техники, а также средств ее технического обслуживания к которым относятся измерительные приборы, системы и комплексы с помощью которых осуществляется контроль параметров вооружения.

Вместе с тем, на сегодняшний день процесс метрологического обслуживания средств измерительного контроля параметров образцов вооружения и военной техники требует усовершенствования, что обеспечит надежное функционирование средств измерительного контроля и образцов вооружения в целом.

Для достижения оптимальной работы системы метрологического обслуживания средств измерительного контроля параметров образцов вооружения и военной техники необходимо проводить оценку эффективности ее работы по определенным показателям.
\end{abstract}


В статье предложен методический подход к оценке эффективности системы метрологического обслуживания средств измерительного контроля параметров образцов вооружения и военной техники, в частности по показателям надежности, времени реагирования системы на отказы и показателями достоверности результатов измерительного контроля.

Ключевые слова: метрологическое обслуживание, вооружение и военная техника, средства измерительного контроля, оценка эффективности.

\title{
Methodological approach to assessing the effectiveness of the metrological maintenance system of measuring instruments for the weapons and military equipment parameters control
}

\author{
Andrii Diadechko * 1 A \\ * Corresponding author: ${ }^{1}$ PhD student of the Technical Support Department, e-mail: andrewvvs@gmail.com, ORCID: 0000-0003-0191-8326 \\ A National Defence University of Ukraine named Ivan Chernyakhovsky, 28, Povitroflotsky Ave., Kyiv, 03049, Ukraine
}

\begin{abstract}
The NATO standards implementation in the field of defense requires us to take certain steps to modernize existing and manufacture new types of weapons and military equipment, as well as means of its maintenance, which include measuring instruments, systems and complexes with the help of which the parameters of weapons are monitored.

At the same time, today the process of metrological maintenance of measuring instruments for weapons and military equipment parameters control requires improvement, which will ensure the reliable functioning of measuring control devices and weapons in general.

To achieve optimal performance of the metrological maintenance system of measuring instruments for weapons and military equipment parameters control, it is necessary to assess the effectiveness of its work according to certain indicators.

The article proposes a methodological approach to assessing the effectiveness of the metrological maintenance system of measuring instruments for the weapons and military equipment parameters control, in particular, in terms of reliability indicators, system response time to failures and certainty indicators of measurement control results.
\end{abstract}

Keywords: metrological maintenance, weapons and military equipment, measuring instruments, efficiency assessment.

\section{References}

1. Khizhnyak V. V. Integral assessment of the metrological support of aviation equipment efficiency. Science and Technology of the Air Force of Ukraine, Kharkiv, HUPS named after I. Kozheduba, 2014, № 3 (16), p.18-20.

2. Kononov V. B., Shevyakov Y. I., Kushneruk Y. I. (2016) Methods for evaluating the effectiveness of planning metrological maintenance of weapons and military equipment samples. Weapons and military equipment systems, Kharkiv, HUPS named after I. Kozheduba, № 2 (46), p.32-34.

3. Dedkov V. K. Formation principles of criteria and indicators of the effectiveness of the complex technical systems functioning. Reliability and quality of complex systems, Moscow, 2013, No. 4, pp. 3-8.

4. Bovda E. M, Guk O. M, Gavrilyuk O. G (2018) Methods for evaluating the effectiveness of the telecommunications networks management system. Modern information technologies in the field of security and defense, № 2 (32), p. 125-134.

5. Chekryzhev N. V., Koptev A. N. Evaluation of the effectiveness of the maintenance process of aircraft onboard systems. Scientific Bulletin of MSTU GA, Moscow, 2015, No. 219, p. 57-64. 
6. Chinkov V. N., Gerasimov S. V., Yakovlev M. Yu. Comprehensive economic indicator of the effectiveness of complex technical objects metrological service. Information processing systems, Kharkiv, KhVU, 2001, Vip. 5 (15), p. 7-12.

7. Vasilevsky O. M., Podzharenko V. O. Indicators standardization of technical means reliability. Textbook, Vinnytsia, VNTU, 2010, $129 \mathrm{p}$.

8. DSTU 2860-94. "Reliability of technology. Terms and definitions". Derzhspozhyvstandart Ukrainy, Kyiv, 1994. 33 p.

9. Gerasimov S. V., Kozlov V. E., Shamayev Y. P. Metrological reliability of measuring equipment: Textbook. - Kharkiv: HUPS, 2006. $175 \mathrm{p}$.

10. Babkov Yu. P. Fundamentals of the reliability theory, maintenance and repair of weapons and military equipment of the Ground Forces Air Defense. Kharkov: KhVU, 1996. 237 p.

12. On approval of the Regulations on the metrological service of the Ukraine Ministry of Defense and the Ukraine Armed Forces. Kyiv: 2017. 15 c. (Order of the Ministry of Defense of Ukraine dated 24.05.2017 № 288 (as amended)).

13. DSTU GOST 8.009: 2008 “GSI. Normalized metrological characteristics of measuring instruments". Derzhspozhyvstandart of Ukraine, Kyiv, 2008.
14. Diadechko A. O., Kuznetsov I. B., Martsenkivsky V. T. (2019) Algorithm for controling the parameters of arms and armament for the military informationmeasuring system. Modern information technologies in the field of security and defense. № 3 (36). Kyiv, 103-108.

15. Wang, Y., Wang, X., Wei, N. The Dicision Analysis for Cost-effectiveness of the Military Metrological support. Metrology \& Measurement Technology, 2007, The Second Artillery Measuring Station, Beijing 100085, China.

16. Girija Moona, Mukesh Jewariya \& Rina Sharma. Relevance of Dimensional Metrology in Manufacturing Industries. MAPAN Journal of Metrology Society of India, CSIR-National Physical Laboratory, New Delhi, India, 2019, № 34, p. 97-104.

17. Salvador Echeverría-Villagómez, Luis Zambrano, Guadalupe Rivera, Marlén López, Diana Guzmán, Francisco Rodriguez. Metrology Investment Projects for Process Effectiveness, NCSLI Workshop \& Symposium, July 2015, Grapeville, TX, USA. Yuanqinga Li, Shilin Wu, Qi Zhang. Construct of Metrology Information Public Service System. 3rd International Conference on Material, Mechanical and Manufacturing Engineering (IC3ME 2015), 2015, p. 1296 1301, DOI: 10.2991/ic3me-15.2015.249. 